\title{
School Psychologists' Knowledge and Self-Efficacy in Working with Students with TBI
}

\author{
Ann E. Glang, Melissa McCart, \& Christabelle L. Moore \\ University of Oregon \\ Susan Davies \\ University of Dayton
}

\begin{abstract}
Approximately 145,000 U.S. children experience lasting effects of traumatic brain injury (TBI) that manifest in social, behavioural, physical, and cognitive challenges in the school setting. School psychologists have an essential role in identifying students who need support and in determining eligibility under the Individuals with Disabilities Education Act. The purpose of this study was to assess the knowledge and perception of abilities related to TBI in a sample of school psychologists currently working in public schools. We surveyed school psychologists and found persistently low levels of knowledge and of perceived preparedness to work with these students. School psychologists with more experience working with students with TBI rated themselves significantly higher on their perceived ability to perform nearly all key duties of a school psychologist. To meet the academic and behavioural needs of students with TBI, all school psychologists need effective training in working with and evaluating students with TBI.
\end{abstract}

Traumatic brain injuries (TBIs) are a leading cause of childhood death and disability worldwide (Faul, Xu, Wald, \& Coronado, 2010). The Centers for Disease Control and Prevention estimates that each year in the United States, 60,000 children are hospitalized with TBI; an additional 700,000 U.S. children visit emergency rooms for symptoms related to TBI (Faul et al., 2010). Brain injury is typically categorized as mild, moderate, or severe based on initial symptoms at the time of injury. Most (70-90\%) TBI-related emergency visits are considered mild (Cassidy et al., 2004; Faul et al., 2010). Children 
with severe injuries are more likely to be hospitalized and to experience more significant disability. Children with moderate and severe injuries are likely to have cognitive, behavioural, and social difficulties that affect their long-term quality of life (Rivara, Vavilala, et al., 2012); with estimates of over $60 \%$ of children with moderate-to-severe TBI and 14\% of children with mild TBI experiencing disability (Rivara, Koepsell, et al., 2012). Overall, approximately 145,000 children experience lasting effects of brain injury that manifest in social, behavioural, physical, and cognitive challenges in the school setting (Zaloshnja, Miller, Langlois, \& Selassie, 2008).

\section{Effects of TBI on School Performance}

Following brain injury, children face multiple challenges that affect school performance (Anderson, Catroppa, Morse, Haritou, \& Rosenfeld, 2005; Gabbe et al., 2014; Hawley, 2004). Challenges with executive functioning, memory, attention, concentration, and processing speed can all impact school performance (Gerrard-Morris et al., 2010; Hawley, Ward, Magnay, \& Mychalkiw, 2004; Moser, Schatz, \& Jordan, 2005). Behavioural or psychological symptoms, impulsivity, and social and emotional issues are also common after TBI (Barlow et al., 2010; Li \& Liu, 2013; Limond, Dorris, \& McMillan, 2009; Ryan et al., 2016) and can negatively affect school performance. This array of challenges can be long lasting, leading to poor long-term school outcomes (Babikian, Merkley, Savage, Giza, \& Levin, 2015; Davies, Fox, Glang, Ettel, \& Thomas, 2013; McKinlay, Dalrymple-Alford, Horwood, \& Fergusson, 2002).

Children injured before age 7 could be at greater risk for significant skill deficits than those injured later in childhood (Anderson \& Moore, 1995). Furthermore, they often have poor long-term outcomes that educators do not attribute to their injuries (Anderson, Catroppa, Morse, Haritou, \& Rosenfeld, 2009; Schwartz et al., 2003). In a study of longterm school outcomes of children with TBI, Prasad, Swank, \& Ewing-Cobbs (2016) found that children with complicated-mild and moderate injuries needed more supports 6 years post-injury than they did 2 years post-injury. This finding emphasizes the need for school teams to track and monitor the progress of students with TBI so they can respond promptly if difficulties emerge and can provide appropriate accommodations or special education services (Prasad et al., 2016). A large portion of children with TBI require interventions or supports beyond what is offered in general education classrooms (Dettmer, Ettel, Glang, \& McAvoy, 2014). Evidence-based instructional methods can help mitigate the academic and behavioural challenges associated with TBI (Ylvisaker et al., 2001). For example, cognitive strategy instructional approaches and Direct Instruction have substantial evidence bases and show preliminary evidence of efficacy with students with TBI (Glang et al., 2008). However, because of a pervasive lack of awareness of TBI among general educators, school teams need support in implementation of effective practices.

\section{Role of School Psychologists}

Because they lead the assessment and evaluation process in school settings, school psychologists need skills, knowledge, and training to accurately evaluate and meet the educational needs of students with TBI (Davies et al., 2013; Hooper, Walker, \& Howard, 2001). Given their extensive training in the assessment, identification, and educational 
intervention of learning and behaviour problems, school psychologists are uniquely positioned to support students with TBI (Davies et al., 2013). As a key member of the educational team that supports students, school psychologists have an essential role and are often viewed as the gatekeepers responsible for identifying students who need support and for determining eligibility under the Individuals with Disabilities Education Act (IDEA). School psychologists also provide guidance to educators about the services appropriate to meeting a student's educational needs (Davies et al., 2013; Davies \& Ray, 2014; Hooper, 2006).

Surprisingly, multiple surveys of school psychologists indicate that they lack the training, knowledge, and skills they need to adequately support students with TBI (Davies et al., 2013; Hooper, 2006). In a survey of school psychologists, respondents endorsed several common misconceptions about TBI (Hooper, 2006), and $83 \%$ of the sample believed that the training they had received was inadequate to work with this student population (Hooper, 2006). In 2013, Davies conducted a survey of program directors and interns regarding how school psychologists are prepared to identify and provide appropriate services for students with TBI. Davies found that none of the school psychology graduate programs devoted a specific course to TBI, and most programs $(75 \%$, $n=42$ ) provided only 61-90 minutes of instruction on the topic (Davies et al., 2013). Additionally, only $25 \%$, or 15 of the 61 interns surveyed, believed they were prepared to serve as an Individual Education Program (IEP) team manager for a student with TBI (Davies et al., 2013). Those findings suggest there is inadequate preparation for these key school personnel. In addition, few school psychology graduate programs approved by the National Association of School Psychologists offer courses in neuropsychology or brain injury, and what training is offered is inadequate (Davies et al., 2013). School psychologists' lack of training in TBI has been identified as a critical area of needed improvement for many years, but little progress has been made to remedy the situation (Davies et al., 2013; Davies \& Ray, 2014; Walker, Stuart Boling, \& Cobb, 1999).

The most recent survey of school psychologists was completed more than 10 years ago (Hooper, 2006), assessed knowledge of TBI only, and was conducted in one state. The purpose of this study was to assess both knowledge and perception of abilities related to TBI in a national sample of school psychologists currently working in public schools. We aimed to answer the following research questions:

1. What is the degree or level of school psychologist knowledge about students with TBI?

2. How do school psychologists perceive their own ability to provide services to students who have TBI and to the educational teams that support them?

3. What types of training have school psychologists received in TBI, and are specific types of training related to TBI knowledge and self-perception of abilities?

4. Are there relationships among school psychologist characteristics, TBI knowledge, and perception of abilities? 


\section{Methods}

\section{Participants}

A total of 232 school psychologists participated in the survey. The demographic variables (see Appendix, Section 1) collected for this sample included (a) current work setting, (b) years of experience as a school psychologist, (c) number of students with TBI worked with in a school setting, (d) level of degree earned, (e) year highest degree was earned, and (f) history of TBI training. An overview of participant characteristics can be found in Table 1.

Table 1.

\section{Demographic Variables of Study Participants (N = 232)}

\begin{tabular}{|c|c|c|}
\hline Variables & $n$ & $\%$ \\
\hline \multicolumn{3}{|l|}{ Current work setting } \\
\hline Public & 210 & 90.5 \\
\hline Private & 4 & 1.7 \\
\hline Hospital & 1 & 0.4 \\
\hline University & 10 & 4.3 \\
\hline Student & 7 & 3.0 \\
\hline \multicolumn{3}{|l|}{ Highest degree obtained } \\
\hline $\mathrm{BA} / \mathrm{BS}$ & 1 & 0.4 \\
\hline MA/MS & 77 & 33.2 \\
\hline Specialist & 105 & 45.3 \\
\hline $\mathrm{EdD} / \mathrm{PhD}$ & 49 & 21.1 \\
\hline \multicolumn{3}{|l|}{ Number of years as a school psychologist } \\
\hline $0-4$ years & 60 & 26.2 \\
\hline $5-10$ & 68 & 29.1 \\
\hline $11-15$ & 39 & 16.8 \\
\hline $16-20$ & 23 & 9.9 \\
\hline More than 20 & 37 & 16.0 \\
\hline Did not respond & 5 & 2.1 \\
\hline Trained in TBI (\% yes) & 133 & 57.3 \\
\hline \multicolumn{3}{|l|}{ Number of students with TBI worked with in a school setting } \\
\hline None & 24 & 10.3 \\
\hline $1-5$ & 146 & 62.9 \\
\hline $6-10$ & 36 & 15.5 \\
\hline 11 or more & 26 & 11.2 \\
\hline $\begin{array}{l}\text { Have a close friend/family member who sustained } \\
\text { concussion/mild brain injury }\end{array}$ & 127 & 54.7 \\
\hline $\begin{array}{l}\text { Have a close friend/family member who sustained } \\
\text { moderate-severe brain injury }\end{array}$ & 49 & 21.1 \\
\hline Have you ever sustained a concussion/mild brain injury? & 55 & 23.7 \\
\hline Have you ever sustained moderate-severe brain injury? & 4 & 1.7 \\
\hline
\end{tabular}


Most of the school psychologists worked in a public school setting (90.5\%) and had obtained an education specialist degree (45\%). About half the sample had worked as a school psychologist for 1-10 years, and sixteen percent of the sample indicated that they had worked as a school psychologist for more than 20 years. More than half $(57 \%)$ indicated that they had prior training in working with students with TBI, and about twothirds of school psychologists reported that they had worked with 1-5 students with TBI within a school setting.

\section{Measures}

TBI knowledge. The TBI Knowledge Survey is a 30-item version adapted for the current study (see Appendix, Section 2) from a validated instrument (Ettel, Glang, Todis, \& Davies, 2016; Hux, Bush, Evans, \& Simanek, 2013). The number of correct items was summed, and a percentage correct computed.

Perception of abilities. We measured self-perception of abilities by asking participants to indicate what they felt qualified to do with students with TBI from a list of common school psychologist responsibilities. The nine-item Perception of Abilities measure (see Appendix, Section 3), adapted from an educator survey (Hux, Walker, \& Sanger, 1996) was modified for school psychologists. For scoring, we summed the number of items selected.

\section{Procedures}

Participants were recruited through the NASP website via a link to the survey. The survey was administered via Survey Console, a secure server on the Internet. When a potential participant accessed the NASP link, they were provided access to the survey and given a unique access number. As compensation, participants were offered the chance to win a $\$ 200$ cash award (out of 5 total).

\section{Data Analysis}

Independent $t$-tests and one-way ANOVA models with Scheffe follow-up tests were used to examine whether TBI knowledge and perceptions of abilities differed by the following teacher characteristics: (a) current work setting, (b) highest degree obtained, (c) history of TBI training, (d) year as a school psychologist, and (e) number of students with TBI worked with in a school setting. Cohen's $d$-statistic (Cohen, 1988) was used as a measure of effect size, following the convention for this measure $(0.2$ small, 0.5 medium, and 0.8 large effect). No allowances for missing data were made since complete data was available for both measures and all teacher characteristics with the exception of years as a school psychologist (2\% missing data). A Bonferroni adjusted $p$-value $<.005$ was used to evaluate statistical significance for tests of group differences. Pearson productmoment correlations were used to examine relationships between school psychologists' characteristics and their knowledge of TBI and self-perception of abilities. 


\section{Results}

The average TBI knowledge score for respondents was $62.7 \%$ ( $S D=9.6$, range 36.786.7). Scores were significantly higher $(t[230]=3.58, p<.001)$ for school psychologists with a history of TBI training $(64.6 \%$ vs. $60.2 \%)$, a moderate effect $(d=.48)$, and significantly higher $(t[230]=3.35, p=.002)$ for psychologists in a non-public work setting versus a public setting $(67.8 \%$ vs. $62.2 \%)$, also a moderate effect $(d=.59)$.

Table 2 presents participants' perceptions of their ability to provide support to students with TBI and their educational teams. Respondents felt most qualified to be part of a multidisciplinary team serving a student with TBI and least qualified to serve as an IEP manager for a student with TBI. Less than $60 \%$ of the respondents rated themselves as qualified to differentiate between students with TBI and other disabilities or to provide appropriate school-based interventions for students with TBI.

Table 2

School Psychologist's Perceived Ability To Support Students with TBI

\begin{tabular}{lc}
\hline Item & $\begin{array}{c}\text { \% Responded } \\
\text { Yes }\end{array}$ \\
\hline Be part of a multidisciplinary team serving a student with TBI & 91.4 \\
Provide accommodations/modifications for students with TBI & 77.2 \\
Monitor classroom behaviour and academic progress of students with TBI & 72.4 \\
Provide assessment services for students who display signs of TBI & 68.1 \\
Provide educators with information about TBI & 57.8 \\
Provide appropriate school-based interventions for students with TBI & 53.9 \\
Differentiate between students with TBI and students with other disabilities & 48.7 \\
Provide students in my school with information about TBI & 47.4 \\
Serve as an IEP manager for a student with TBI & 27.6 \\
\hline
\end{tabular}

Of those who received TBI training, 57\% indicated that they had attended a class or seminar specifically devoted to $\mathrm{TBI} ; 73 \%$ had attended a poster presentation, miniseminar, or in-service; and $74 \%$ had been to a conference or workshop. Table 3 shows the correlations among type of training, TBI knowledge score, and perception of ability on school psychologist responsibilities.

Table 3

Correlation Between Type of Training and School Psychologists' Perception of Ability in Supporting Students with TBI

\begin{tabular}{lllll}
\hline Variable & $\mathbf{1}$ & $\mathbf{2}$ & $\mathbf{3}$ & $\mathbf{4}$ \\
\hline 1. Class seminar & - & & & \\
2. Poster presentation, mini-seminar, or in-service & .01 & \multicolumn{2}{l}{} & \\
3. Conference or workshop & .14 & $.22^{*}$ & \\
4. Perception of abilities & $.22^{*}$ & $.22^{*}$ & $.26^{*}$ \\
\hline${ }^{*} p<.05$. & & &
\end{tabular}


We computed Pearson product-moment correlation coefficients to assess the relationship between school psychologists' characteristics and their knowledge of TBI and self-perception of abilities. More years of working as a school psychologist was significantly correlated with greater TBI knowledge scores $(r=.21)$, a moderately small effect. Having worked with more students with TBI in a school setting was significantly correlated with greater TBI knowledge scores $(n=232, r=.34, p<.001)$, a moderate effect. Increased knowledge of TBI was positively associated with number of years as a school psychologist $(n=227, r=.21, p=.002)$. There was no significant relationship between highest degree achieved and knowledge of TBI nor between highest degree achieved and perception of ability (see Table 4). The number of students with TBI a participant had worked with was positively correlated with the perceived ability to carry out most of the duties of a school psychologist.

Table 4

Perception of Ability Scores by School Psychologist Characteristics

\begin{tabular}{|c|c|c|c|c|c|}
\hline Characteristic & Mean* & $S D$ & Test Statistic & $p$ & $d$ \\
\hline Current work setting & & & $t[230]=1.08$ & .281 & .25 \\
\hline Public & $5.39_{a}$ & 2.42 & & & \\
\hline Non-public & $6.00_{a}$ & 3.49 & & & \\
\hline Highest degree obtained & & & $F[2,231]=0.85$ & .430 & .17 \\
\hline MA/MS or BA/BS & $5.14 a$ & 2.69 & & & \\
\hline Specialist & $5.62 a$ & 2.30 & & & \\
\hline $\mathrm{EdD} / \mathrm{PhD}$ & $5.55_{a}$ & 2.79 & & & \\
\hline History of TBI training & & & $t[230]=5.12$ & $<.001$ & .68 \\
\hline No & $4.50_{a}$ & 2.42 & & & \\
\hline Yes & $6.14_{b}$ & 2.40 & & & \\
\hline Years as a school psychologist & & & $F[5,226]=0.94$ & .456 & .29 \\
\hline $0-5$ years & $5.10_{a}$ & 2.59 & & & \\
\hline $6-10$ & $5.35_{a}$ & 2.48 & & & \\
\hline $11-15$ & $5.67 \mathrm{a}$ & 2.16 & & & \\
\hline $16-20$ & $5.26_{a}$ & 2.67 & & & \\
\hline $21-25$ & $6.43_{a}$ & 2.38 & & & \\
\hline 26 or more years & $5.87 \mathrm{a}$ & 2.87 & & & \\
\hline $\begin{array}{l}\text { Number of students with TBI worked } \\
\text { with in a school setting }\end{array}$ & & & $F[3,331]=16.44$ & $<.001$ & .93 \\
\hline 0 & $3.58_{a}$ & 2.47 & & & \\
\hline $1-5$ & $5.11_{b}$ & 2.29 & & & \\
\hline $6-10$ & $6.42_{c}$ & 2.63 & & & \\
\hline More than 10 & $7.69_{c}$ & 1.78 & & & \\
\hline
\end{tabular}

* Means that do not share the same subscript significantly differ from each other at $p<.05$. 


\section{Discussion}

The results of this survey suggest that in this national sample of school psychologists, knowledge about TBI was low. The average TBI knowledge score for respondents was $62.7 \%$, with school psychologists with a history of TBI training scoring slightly higher. Similar rates of knowledge about TBI among school psychologists were reported more than 10 years ago by Hooper (2006), suggesting little change in TBI knowledge and awareness over time among these key school professionals.

Although most of the respondents reported feeling qualified to perform some of the core responsibilities of a school psychologist for supporting students with TBI (e.g., be part of a multidisciplinary team, monitor classroom behaviour, provide accommodations and modifications), a surprisingly low percentage of the sample reported feeling qualified to perform other important duties. For example, only $68 \%$ of the sample felt prepared to conduct an assessment with a student with TBI, and less than half rated themselves as qualified to differentiate TBI from other disabilities or to conduct effective assessments for eligibility. This finding could reflect the problem of a lack of pre-service training in graduate training programs and the complexities of evaluating students with developmental injuries. Given the overlap between behavioural manifestations of effects of TBI and other disabilities, such as learning disabilities and emotional and behavioural disorders, without communication from parents or medical providers about the student's injury and prognosis, it can be very difficult to differentiate TBI from other disabilities.

Not surprisingly, school psychologists with more experience working with students with TBI rated themselves significantly higher on their perceived ability to perform nearly all key duties of a school psychologist. The same pattern was found by Davies et al. (2013), who asked school psychology interns to rate their perceived preparedness on the same scale. Training in TBI was also significantly related to school psychologists' perceptions of their own ability to provide services for students with TBI. This finding emphasizes the importance of providing pre-service training in supporting students with TBI. That is, if school psychologists are provided with training on TBI, they are potentially better equipped to assess, monitor, and recommend appropriate services to students with TBI.

School psychologists work in concert with a network of school- and communitybased professionals involved in caring with children who have sustained TBIs, including teachers, speech therapists, occupational therapists, physical therapists, tutors, counselors, physicians, neuropsychologists, athletic trainers, and coaches. The participants in this study reported a high degree of confidence in serving as a part of a multidisciplinary team serving a student with TBI; this is a familiar role for school psychologists. However, they were least confident in their ability to serve as the manager of the IEP for a student with TBI. This may be, in part, because many school psychologists are not expected to write IEPs; it may also reflect their discomfort with taking on a leadership role in TBI cases.

School psychologists have a multi-faceted and complex role in the school setting; they are experts in learning, behaviour, and mental health. Although most school psychologists engage in a variety of activities, including consultation, intervention, and counseling, a significant part of their time is often spent on assessment (Fagan \& Wise, 2007). Their lack of knowledge and of perceived ability to perform important job 
functions, such as assessing and differentiating students with TBI from students with other disabilities, could lead to the under-identification of students with TBI for special education. Estimates suggest that there are 145,000 children in school $(\mathrm{K}-12)$ at any given time with long-term TBI-related disability (Zaloshnja et al., 2008). However, only about 26,000 students receive special education services under the TBI category (U.S. Department of Education, National Center for Education Statistics, 2016), suggesting that students with TBI are significantly under-identified in the United States. Because special education identification rarely occurs after the first year post-injury, children whose disability emerges over time may be misidentified or may not be identified at all (Taylor et al., 2003). State directors of special education confirm that many students with TBI are inappropriately identified (Glang et al., 2015). State directors reported that the inaccuracy was likely due to misidentification of students with TBI. Specifically, in only $40 \%$ of cases were students with TBI identified under the category of TBI; students with TBI were more often identified under the categories of Specific Learning Disability, Other Health Impairment, and Emotional Disturbance. Although identification for special education eligibility is the result of an evaluation conducted by a multidisciplinary team, the school psychologist conducts the majority of academic, psychosocial, and intellectual assessments and takes the lead in synthesizing data into reports that are presented to the multidisciplinary team. Accurate identification of students with TBI is not possible without the collaboration of school psychologists, parents, and medical professionals. Furthermore, for school psychologists to become more knowledgeable about brain injury, it is crucial that graduate training programs provide explicit training on identifying, evaluating, and supporting students with TBI.

\section{Limitations}

This study's limitations centre on the survey sample and measure. First, all survey participants were volunteers, with inherent biases. Because most participants had a personal connection to TBI and more than half had training in TBI, the participants in this sample might have been more knowledgeable and confident in the area of TBI than typical school psychologists. For this reason, it is unclear the extent to which results can be generalized to the larger population. However, assuming that practitioners in general are less knowledgeable and confident than the participants in this sample underscores the importance of providing pre-service school psychologists with training in TBI.

Neither of the measures used in this study assessed school psychologists' skills in actually working with students. The Perception of Abilities measure assessed self-efficacy in performing the responsibilities of a school psychologist with students with TBI. Previous research has shown that educators with higher self-efficacy are more supportive of students with disabilities than those with lower self-efficacy and that their students have higher achievement (Guo, Connor, Yang, Roehrig, \& Morrison, 2012). The TBI Knowledge Survey, adapted from a previously validated instrument (Hux et al., 2013; Hux et al., 1996), assesses knowledge of TBI facts and information rather than actual performance. Although knowledge and self-efficacy are theoretically linked to behaviour (Ajzen, 1991; Ajzen, Joyce, Sheikh, \& Cote, 2011), a more effective approach to gauging school psychologist skill with students with TBI would include observational measures. 


\section{Conclusion}

The results of this study demonstrate a continued need for training on TBI for school psychologists. According to the results of this survey, many school psychologists have some basic misconceptions and knowledge gaps about TBI and about the effects of brain injury on students. This lack of knowledge on the part of school psychologists - the gatekeepers for access to special education services - could lead to the misidentification and under-identification of students with TBI for special education, at least in part. To remedy this situation, school psychologists need training in (a) screening for TBI in all suspected disability cases, (b) assessment of students with a known or suspected TBI, (c) designing appropriate educational plans for students with TBI, and (d) educating others in the school community about TBI.

Training school psychologists is an important and necessary first step in improving appropriate identification of students with TBI for special education services. This training needs to occur both at the pre-service level in graduate preparation programs and through professional development sessions for experienced practitioners.

Children who have sustained TBIs need an advocate in the school who understands their unique needs. The well trained school psychologist can serve as a team leader and liaison, helping the school, family, and community-based providers to understand the importance of a coordinated treatment plan. The school psychologist can also assist teachers with progress monitoring to evaluate the student's response to intervention, particularly during the recovery process. This can ensure that interventions are intensified, changed, or removed as necessary. Further, many students struggle with emotional distress related to memory problems, learning differences, and friendship changes that can occur after a TBI. The school psychologist can be a key source of emotional support by providing counseling and helping to create a safe, supportive environment for the student at school.

Additional change in practice will come only with modifications in policy and implementation of evidence-based practices in effective assessment and instruction (Dettmer et al., 2014; Glang, Todis, Sublette, Eagan-Brown, \& Vaccaro, 2010). For example, directors of graduate programs in school psychology can review program curricula and determine how instruction on TBI can better be integrated into existing coursework. This might include more TBI-specific assessment and intervention cases, more direct instruction on unique facets of working with students with TBI, and more hands-on experiences with TBI cases in practicum. School psychologists have expertise in assessment, identification, and intervention with students with disabilities (Davies et al., 2013) and are uniquely positioned to lead efforts to improve services for students with TBI.

\section{References}

Ajzen, I. (1991). The theory of planned behavior. Organizational Behavior Human Decision Processes, 50, 179-211.

Ajzen, I., Joyce, N., Sheikh, S., \& Cote, N. G. (2011). Knowledge and the prediction of behavior: The role of information accuracy in the theory of planned behavior. Basic and Applied Social Psychology, 33, 101-117. 
Anderson, V. A., Catroppa, C., Morse, S., Haritou, F., \& Rosenfeld, J. (2005). Attentional and processing skills following traumatic brain injury in early childhood. Brain Injury, 19(9), 699-710. doi:10.1080/02699050400025281

Anderson, V., Catroppa, C., Morse, S., Haritou, F., \& Rosenfeld, J. V. (2009). Intellectual outcome from preschool traumatic brain injury: A 5 -year prospective, longitudinal study. Pediatrics, 124(6), 1064-1071.

Anderson, V., \& Moore, C. (1995). Age at injury as a predictor of outcome following pediatric head injury: A longitudinal perspective. Child Neuropsychology, 1(3), 187-202.

Babikian, T., Merkley, T., Savage, R. C., Giza, C. C., \& Levin, H. (2015). Chronic aspects of pediatric traumatic brain injury: Review of the literature. Journal of Neurotrauma, 32(23), 1849-1860. doi:10.1089/neu.2015.3971

Barlow, K. M., Crawford, S., Stevenson, A., Sandhu, S. S., Belanger, F., \& Dewey, D. (2010). Epidemiology of postconcussion syndrome in pediatric mild traumatic brain injury. Pediatrics, 126(2), 374-381. doi:peds.2009-0925 [pii] 10.1542/peds.2009-0925

Cassidy, J. D., Carroll, L. J., Peloso, P. M., Borg, J., von Holst, H., Holm, L., ...Coronado, V. G. (2004). Incidence, risk factors and prevention of mild traumatic brain injury: Results of the WHO Collaborating Centre Task Force on Mild Traumatic Brain Injury. Journal of Rehabilitation Medicine(43 Suppl), 28-60.

Cohen, J. (1988). Statistical power analysis for the behavioral sciences (2nd ed.). Hillsdale, NJ: Erlbaum \& Associates.

Davies, S., Fox, E., Glang, A., Ettel, D., \& Thomas, C. (2013). Traumatic brain injury and teacher training: A gap in educator preparation. Physical Disabilities: Education and Related Services, 32(1), 55-65.

Davies, S. C., \& Ray, A. M. (2014). Traumatic brain injury: The efficacy of a half-day training for school psychologists. Contemporary School Psychology, 18(1), 81-89.

Dettmer, J., Ettel, D., Glang, A., \& McAvoy, K. (2014). Building statewide infrastructure for effective educational services for students with TBI: Promising practices and recommendations. The Journal of Head Trauma Rehabilitation, 29(3), 224-232. doi:10.1097/HTR.0b013e3182a1cd68

Ettel, D., Glang, A. E., Todis, B., \& Davies, S. C. (2016). Traumatic brain injury: Persistent misconceptions and knowledge gaps among educators. Exceptionality Education International, 26(1), 1-18.

Fagan, T. K., \& Wise, P. S. (2007). School psychology: Past, present, and future (3rd ed.). Bethesda, MD: National Association of School Psychologists.

Faul, M., Xu, L., Wald, M., \& Coronado, V. (2010). Traumatic brain injury in the United States: Emergency department visits, hospitalizations and deaths 2002-2006. Atlanta, GA: US Centers for Disease Control and Prevention. Retrieved from http://www.cdc.gov /traumaticbraininjury/pdf/blue_book.pdf

Gabbe, B. J., Brooks, C., Demmler, J. C., Macey, S., Hyatt, M. A., \& Lyons, R. A. (2014). The association between hospitalisation for childhood head injury and academic performance: Evidence from a population e-cohort study. Journal of Epidemiology \& Community Health, 68(5), 466-470. doi:10.1136/jech-2013-203427

Gerrard-Morris, A., Taylor, H. G., Yeates, K. O., Chertkoff Walz, N., Stancin, T., Minich, N., \& Wade, S. L. (2010). Cognitive development after traumatic brain injury in young children. Journal of the International Neuropsychological Society, 16(1), 157-168. doi:10.1017/s1355617709991135 
Glang, A., Ettel, D., Todis, B., Gordon, W. A., Oswald, J. M., Vaughn, S. L., ... Brown, M. (2015). Services and supports for students with traumatic brain injury: Survey of state educational agencies. Exceptionality, 23(4), 211-224. doi:10.1080/09362835.2014.986612

Glang, A., Todis, B., Sublette, P., Eagan-Brown, B., \& Vaccaro, M. (2010). Professional development in TBI for educators: The importance of context. Journal of Head Trauma Rehabilitation, 25(6), 426-432.

Glang, A., Ylvisaker, M., Stein, M., Ehlhardt, L., Todis, B., \& Tyler, J. (2008). Validated instructional practices: Application to students with traumatic brain injury. Journal of Head Trauma Rehabilitation, 23(4), 243-251.

Guo, Y., Connor, C., Yang, Y., Roehrig, A., \& Morrison, F. (2012). The effects of teacher qualification, teacher self-efficacy, and classroom practices on fifth graders' literacy outcomes. The Elementary School Journal, 113(1), 3-24.

Hawley, C. A. (2004). Behaviour and school performance after brain injury. Brain Injury, 18(7), 64559. doi:10.1080/02699050310001646189

Hawley, C. A., Ward, A. B., Magnay, A. R., \& Mychalkiw, W. (2004). Return to school after brain injury. Archives of Disease in Childhood, 89(2), 136-142.

Hooper, S. R. (2006). Myths and misconceptions about traumatic brain injury: Endorsements by school psychologists. Exceptionality, 14(3), 171-182.

Hooper, S. R., Walker, N. W., \& Howard, C. (2001). Training school psychologists in traumatic brain injury. The North Carolina model. North Carolina Medical Journal, 62(6), 350-354.

Hux, K., Bush, E., Evans, K., \& Simanek, G. (2013). Misconceptions about traumatic brain injury among students preparing to be special education professionals. Support for Learning, 28(3), 109-114. doi:10.1111/1467-9604.12028

Hux, K., Walker, M., \& Sanger, D. D. (1996). Traumatic brain injury: Knowledge and selfperceptions of school speech-language pathologists. Language, Speech, and Hearing Services in Schools, 27(2), 171-184.

Li, L., \& Liu, J. (2013). The effect of pediatric traumatic brain injury on behavioral outcomes: A systematic review. Developmental Medicine \& Child Neurology, 55(1), 37-45. doi:10.1111/j.1469-8749.2012.04414.x

Limond, J., Dorris, L., \& McMillan, T. M. (2009). Quality of life in children with acquired brain injury: Parent perspectives 1-5 years after injury. Brain Injury, 23(7/8), 617-622.

McKinlay, A., Dalrymple-Alford, J. C., Horwood, L. J., \& Fergusson, D. M. (2002). Long term psychosocial outcomes after mild head injury in early childhood. Journal of Neurology, Neurosurgery \& Psychiatry, 73(3), 281-288.

Moser, R. S., Schatz, P., \& Jordan, B. D. (2005). Prolonged effects of concussion in high school athletes. Neurosurgery, 57(2), 300-306.

Prasad, M. R., Swank, P. R., \& Ewing-Cobbs, L. (2017). Long-term school outcomes of children and adolescents with traumatic brain injury. Journal of Head Trauma Rehabilitation, 32(1), E24E32. doi:10.1097/HTR.0000000000000218

Rivara, F. P., Koepsell, T. D., Wang, J., Temkin, N., Dorsch, A., Vavilala, M. S., ... Jaffe, K. M. (2012). Incidence of disability among children 12 months after traumatic brain injury. American Journal of Public Health, 102(11), 2074-2079.

Rivara, F. P., Vavilala, M. S., Durbin, D., Temkin, N., Wang, J., O'Connor, S. S., ... Jaffe, K. M. (2012). Persistence of disability 24 to 36 months after pediatric traumatic brain injury: A cohort study. Journal of Neurotrauma, 29(15), 2499-2504. 
Ryan, N. P., Catroppa, C., Godfrey, C., Noble-Haeusslein, L. J., Shultz, S. R., O’Brien, T. J., ... Semple, B. D. (2016). Social dysfunction after pediatric traumatic brain injury: a translational perspective. Neuroscience \& Biobehavioral Reviews, 64, 196-214. doi:10.1016/j.neubiorev.2016.02.020

Schwartz, L., Taylor, H. G., Drotar, D., Yeates, K. O., Wade, S. L., \& Stancin, T. (2003). Long-term behavior problems following pediatric traumatic brain injury: Prevalence, predictors, and correlates. Journal Of Pediatric Psychology, 28(4), 251-263. doi:10.1093/jpepsy/jsg013

Taylor, H. G., Yeates, K. O., Wade, S. L., Drotar, D., Stancin, T., \& Montpetite, M. (2003). Longterm educational interventions after traumatic brain injury in children. Rehabilitation Psychology, 48(4), 227-236. doi:10.1037/0090-5550.48.4.227

U.S. Department of Education, National Center for Education Statistics. (2016). Table 204.30. Children 3 to 21 years old served under Individuals with Disabilities Education Act (IDEA), Part B, by type of disability: Selected years, 1976-77 through 2013-14. Digest of Education Statistics, 2015 (NCES 2016-014). Washington, DC: Author. Retrieved from https://nces.ed.gov/fastfacts /display.asp?id $=64$

Walker, N. W., Stuart Boling, M., \& Cobb, H. (1999). Training of school psychologists in neuropsychology and brain injury: Results of a national survey of training programs. Child Neuropsychology, 5(2), 137-142.

Ylvisaker, M., Todis, B., Glang, A. P., Urbanczyk, B., Franklin, C., DePompei, R., ... Siantz, J. (2001). Educating students with TBI: Themes and recommendations. Journal of Head Trauma Rehabilitation February, 16(1), 76-93.

Zaloshnja, E., Miller, T., Langlois, J. A., \& Selassie, A. W. (2008). Prevalence of long-term disability from traumatic brain injury in the civilian population of the United States, 2005. Journal of Head Trauma Rehabilitation, 23(6), 394-400. doi:10.1097/01.HTR.0000341435.52004.ac

\section{Authors' Note}

This work was supported in part by grant \#H133B090010 made by the National Institute on Disability and Rehabilitation Research to the Cincinnati Children's Hospital Medical Center and the University of Oregon. The authors thank Elizabeth Backus, Laura Beck, and Jeff Gau for their assistance in the preparation of this manuscript.

Correspondence concerning this article should be addressed to Dr. Ann E. Glang, Center on Brain Injury Research \& Training, University of Oregon, 1600 Millrace, Suite 202, Eugene, OR, 97403, U.S.A. Email: aglang@uoregon.edu 


\section{Appendix \\ School Psychologist TBI Survey}

\section{Section 1: Demographics}

Your current work setting:

- Public

- Private

- Hospital

- University

○ Student

Do you have experience as a school psychologist?

- Yes

$\circ$ No

Number of years as a school psychologist:

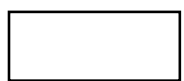

Approximately how many students with TBI have you worked with in a school setting?

$\circ$ none (0)

$\circ$ few $(1-5)$

○ several (6-10)

$\circ$ many $(>11)$

Type of Highest Degree Earned:

○ Bachelor

- Master

○ Specialist

○ Doctorate

\section{Year of Highest Degree Earned:}

○ before 1970

- 1971-1980

○ $1981-1990$

○ 1991-2000

○ 2000-2010

○ 2011-2012

Were you trained or are you being trained in traumatic brain injury (TBI)?
○ Yes
$\circ$ No

If YES, describe what kind of training you received:

Class/seminar specifically devoted to TBI

Poster presentation, mini seminar, or in service

Conference or workshop

\begin{tabular}{cc} 
Yes & No \\
\hline 0 & 0 \\
0 & 0 \\
0 & 0 \\
\hline
\end{tabular}


Please list any TBI resources that were used in your training (e.g., websites, books, etc.):

Do you have a close friend or family member who has ever sustained a:

Concussion/mild brain injury

Moderate-severe brain injury

\begin{tabular}{cc} 
Yes & No \\
\hline & $\circ$ \\
0 & 0
\end{tabular}

Have you ever sustained a:

Concussion/mild brain injury

Moderate-severe brain injury

\begin{tabular}{cc} 
Yes & No \\
\hline & 0 \\
$\circ$ & 0 \\
\hline
\end{tabular}

\section{Section 2: TBI Knowledge Survey}

Please answer the following:

1) TBI is equally common in males and females

2) A child/adolescent in a coma is usually not aware of what is happening around them.

3) After a brain injury, children/adolescents can forget who they are and not recognize others but be 'normal' in every other way.

4) A brain injury affects girls' and boys' brains differently.

5) Even after several weeks in a coma, when children/adolescents wake up, most recognize and speak to others right away.

6) After a brain injury, it is usually harder to learn new things than it is to remember things from before the injury.

7) A child/adolescent's pre-injury status (i.e., intellectual and emotional $\quad \circ \quad \circ$ functioning) is likely to impact recovery from the brain injury.

8) Children/adolescents who have had one brain injury are more likely to $\circ \quad \circ$ have a second one.

9) Complete recovery from severe brain injury is not possible no matter $\quad \circ$ how badly the child/adolescent wants to recover.

10) Children/adolescents are likely to recover more completely from a brain $\quad \circ$ injury than adults due to the greater plasticity of the young brain.

11) A child who acquires a brain injury between 12 and 16 will typically $\quad \circ \quad 0$ present an even pattern of academic strengths and weaknesses.

12) A child's brain, unlike an adult's, is able to bounce back after a brain $\quad \circ \quad 0$ injury.

13) It is common for children/adolescents with brain injuries to be easily $\quad \circ$ angered.

14) Fluctuation among cognitive abilities is a finding typical of

0
children/adolescents who have a brain injury and is not typical of the general population of children/adolescents.

15) When children/adolescents are knocked unconscious, most wake up quickly with no lasting effects. 
16) It is important to provide many details when delivering instructions to a student with brain injury.

17) Greater variability exists in the population of students with TBI than exists in populations of others students with disabilities.

18) The only sure way to tell if someone has suffered brain impairment from a brain injury is by an X-ray of the brain.

19) Knowing the location of a TBI helps in the development of programming to meet a student's needs.

20) Many students with TBI display characteristics similar to those of students with a learning disability.

21) Knowledge of a student's background prior to TBI is necessary when developing an educational plan.

22) Medical labels that specify TBI as mild, moderate, or severe are useful for programming communication and academic services.

23 ) The primary goal of brain injury rehabilitation is to increase physical abilities such as walking.

24) Many students with TBI perform better in structured testing situations than they do in classroom settings.

25) The challenges of students with TBI are typically more difficult to assess than the challenges of students with other disabilities.

26) Most special and regular educators are knowledgeable about the speech, language, and cognitive communication problems associated with TBI.

27) Students with TBI often have trouble forming and maintaining friendships.

28) Recovery following TBI can continue for several years.

29) Students with TBI often display behavior problems.

30) Standardized tests are more beneficial than descriptive measures (e.g., language samples, interviews, checklists, observational techniques) in assessing cognitive deficits secondary to TBI.

\section{Section 3: Perception of Abilities}

Which of the following do you feel qualified to do at the present time? (check all that apply)

$\circ$ Be part of a multidisciplinary team serving a student with TBI.

- Serve as an IEP manager for a student with TBI.

- Provide educators with information about TBI.

- Provide students in my school with information about TBI.

- Provide assessment services for students who display signs of TBI.

- Provide appropriate school-based interventions for students with TBI.

- Provide accommodations or modifications for students with TBI, such as modifying the school day, modifying the classroom environment, or modifying the school environment.

- Differentiate between students with TBI and students with other disabilities.

- Monitor classroom behavior and academic progress for students with TBI.

What are your primary concerns about providing services to students with TBI (e.g., personal continuing education needs, academic programming for students, education of school personnel about TBI, transitioning students from medical facilities to schools, etc.)? 